\begin{tabular}{|c|c|}
\hline $\mathbf{N} \mathbf{D} \mathbf{R}$ & Management and Business Review \\
\hline $\begin{array}{r}\text { MANAGEMENT \& } \\
\text { BUSINESS REVIEW } \\
\end{array}$ & $\begin{array}{l}\text { Available at } \frac{\text { http://ejournal.unikama.ac.id/index.php/mbr }}{\text { ISSN: } 2541-5808 \text { (online) }}\end{array}$ \\
\hline
\end{tabular}

\title{
Pengaruh Experiental Marketing terhadap loyalitas konsumen dan dimediasi oleh kepuasan konsumen
}

\author{
Deni Widyo Prasetyo', Wasis ${ }^{2}$ \\ 1,2 Program Studi Manajemen STIE PGRI Dewantara Jombang, Indonesia \\ Email: Deni.dewantara@gmail.com
}

\begin{tabular}{|c|c|}
\hline \multicolumn{2}{|c|}{ Article Info: } \\
\hline Receive & : Okt 2019 \\
\hline Revised & : Nop 2019 \\
\hline Accepted & : Des 2019 \\
\hline Published & : Des 2019 \\
\hline DOI & : 10.21067/mbr.v3i2.4616 \\
\hline Copyright & $\begin{array}{l}\text { : Management and } \\
\text { Business Review }\end{array}$ \\
\hline
\end{tabular}

Keywords:

Experiental Marketing, Consumer

Satisfaction, and Consumer Loyalty

\begin{abstract}
This study aims to determine and explain the effect of Experiental Marketing on consumer loyalty and is mediated by consumer satisfaction. In this study using an explanatory method (explanatory) with a Likert measurement scale, the sample used as many as 100 samples, data collection methods with documentation, questionnaires and observations. Data analysis used descriptive analysis, mediation regression analysis, hypothesis testing, and Sobel test. The results showed that the concept of applying Experiental Marketing had no effect on consumer loyalty in Jos cafe Jombang, consumer satisfaction has a positive effect on consumer loyalty at Jombang cafe Jombang, consumer satisfaction positively influences Experiental Marketing mediation on consumer loyalty in Jos Cafe Jombang. Suggestions in further research is to be able to describe Experiental Marketing, consumer satisfaction and customer loyalty in Jos Cafe Jombang as a whole need to do research by using a larger sample and in a longer research period.
\end{abstract}

\begin{abstract}
Abstrak: Penelitian ini bertujuan untuk mengetahui dan menjelaskan pengaruh Experiental Marketing terhadap loyalitas konsumen dan dimediasi oleh kepuasan konsumen. Penelitian menggunakan metode explanasi (explanatory) dengan skala pengukuran Likert 5 point, sampel yang digunakan sebanyak 100 sampel, metode pengumpulan data dengan angket. Analisis data menggunakan analisis deskriptif, Analisa Jalur, dan Uji Sobel. Hasil penelitian menunjukan bahwa penerapan Experiental Marketing tidak berpengaruh terhadap loyalitas konsumen di Jos cafe Jombang, kepuasan konsumen berpengaruh positif terhadap loyalitas konsumen di Jos cafe Jombang, kepuasan konsumen berpengaruh positif menjadi mediasi Experiental Marketing terhadap loyalitas konsumen di Jos Cafe Jombang. Saran dalam penelitian selanjutnya yaitu agar dapat menggambarkan Experiental Marketing, Kepuasan konsumen dan loyalitas konsumen di Jos cafe jombang secara menyeluruh perlu dilakukan penelitian dengan menggunakan sampel yang lebih besar dan dalam jangka waktu penelitian yang lebih panjang.
\end{abstract}




\section{Pendahuluan}

Perusahaan membutuhkan strategi pemasaran yang tepat agar perusahaan dapat mempertahankan konsumen dalam kondisi apapun. Menurut Zeithaml et al. (2000) tujuan akhir dari keberhasilan sebuah perusahaan yang menjalin hubungan relasi dengan konsumennya adalah untuk membentuk loyalitas yang kuat. Perusahaan saat ini tidak hanya berusaha mencari pembeli tetapi mereka berusaha agar pembeli (consumer) dapat meningkat menjadi pelanggan (customer) yang selanjutnya diusahakan menjadi pelanggan tetap (client). Usaha ini dilakukan karena pembeli yang menjadi pelanggan tetap merupakan indikator bahwa pembeli tersebut telah menjadi loyal terhadap perusahaan atau produk yang ditawarkan kepadanya.

Pemasaran saat ini terus berkembang dan berubah, dari konsep yang konvensional menuju konsep pemasaran modern. Faktor-faktor seperti meningkatnya jumlah pesaing, kecanggihan teknologi, dan meningkatnya edukasi mengenai pemasaran, semakin mempercepat dan memacu para pemasar untuk semakin kreatif memasarkan produknya. Zarem (2000) mengutip pernyataan Sanders, direktur Yahoo, yang menyatakan bahwa "Pengalaman merupakan dasar perekonomian baru untuk semua industri". Lebih lanjut Sanders menyatakan bahwa saat ini adalah masanya experience economy. Tanpa mempedulikan produk atau jasa yang dijual, seorang pemasar perlu memberikan pengalaman yang tidak terlupakan bagi konsumenya karena hal inilah yang sangat mereka hargai.

Pine \& Gilmore (2011) mengatakan pengalaman (experience) merupakan penawaran ekonomi keempat setelah komoditi, barang dan jasa. Menurutnya ketika seseorang membeli sebuah pengalaman, ia membayar untuk menghabiskan waktu menikmati rangkaian acara berkesan dimana perusahaan mengajaknya dengan cara yang melekat dengan pribadinya. Beberapa perusahaan mulai menerapkan suatu konsep penciptaan pengalaman yang tidak terlupakan (memorable experience) bagi konsumen, yang sekarang dikenal dengan istilah experiential marketing), yaitu suatu konsep pengembangan strategi pemasaran yang menekankan aspek emosional dalam menciptakan pengalaman pelanggan selama menggunakan suatu produk atau jasa.

Seperti disampaikan oleh salah satu pakar marketing Indonesia, Kartajaya (2002) bahwa dalam teori experiential marketing, dikatakan bahwa feeling yang bagus akan membuat pelanggan mampu berpikir positif. Kemudian dilanjutkan, tugas experiental marketer adalah melakukan pengaruh external untuk digabungkan dengan kondisi feel dan think yang ada di dalam diri pelanggan, untuk menjadi suatu aksi memorable experience.

Experiental marketing adalah tentang suatu perusahaan yang membuat konsumennya bisa lebih loyal, dengan cara memaksimalkan kelima unsur (Schmitt, 1999), yakni: unsur sense; menyangkut panca indera (seperti penglihatan, pendengaran, dan penciuman) yang dapat dilakukan dengan memberikan 
pemandangan yang indah, aroma yang enak, sentuhan yang nyaman, musik yang sesuai. Unsur feel merupakan perasaan dan emosi positif yang timbul, bagaimana menciptakan perasaan enak (feel good) bagi para konsumen. Unsur think adalah kreatif yang muncul di benak pelanggan dari sebuah merek, dengan cara membuat pelanggan berpikir positif terhadap produk tersebut. Unsur act menyangkut tindakan fisik dan interaksi yang muncul, yaitu dengan membuat pelanggan lebih aktif dengan produk tersebut. Sedangkan unsur relate adalah upaya menghubungkan merek dengan konsumen itu sendiri, orang lain, atau budaya. Penelitian Jeon (2013) menyatakan bahwa konsep experiental marketing berpengaruh positif secara langsung terhadap loyalitas konsumen.

Namun demikian untuk menjadikan pembeli agar menjadi loyal bukan merupakan hal yang mudah dilakukan. Hal ini disebabkan terdapat banyak tantangan yang harus dihadapi dan dipertimbangkan agar konsumen menjadi loyal. Secara konsep dapat dikatakan bahwa untuk menjadikan konsumen loyal maka perusahaan harus membuat konsumen tersebut puas terlebih dahulu. Kepuasan konsumen hanya bisa muncul jika perusahaan mampu memenuhi kebutuhan (needs) dan keinginan (wants) konsumen yang sangat bervariasi. Kebutuhan dan keinginan konsumen yang berbeda-beda tersebut harus dapat ditangkap oleh perusahaan dengan menyediakan produk dengan kualitas dan harga yang sesuai dengan kemampuan konsumen. Selain fakta tersebut, hal lain yang harus dilaksanakan oleh perusahaan untuk memenuhi kebutuhan dan keinginan konsumen dalam rangka meningkatkan kepuasan serta menciptakan loyalitas adalah suatu perusahaan harus melakukan pengenalan danpendekatan kepada konsumen (consumer intimacy). Tujuannya adalah agar konsumen memiliki ikatan emosional dengan perusahaan.

Perusahaan harus benar benar memenuhi kebutuhan dan keinginan konsumen agar konsumen tersebut merasa puas dan tetap bertahan. Menurut Mowen \& Michael (2005) kepuasan konsumen merupakan keseluruhan sikap konsumen setelah memperoleh dan menggunakan barang dan layanan. Oleh karena itu perusahaan harus mampu memenuhi kebutuhan dan keinginan konsumen dan lebih jauh lagi dapat menciptakan loyalitas konsumen.

Experiental marketing merupakan upaya pengembangan konsep pemasaran dalam menghadapi perubahan yang terjadi di pasar. Pemasar berusaha melibatkan pelanggan secara emosional dan psikologikal ketika mengkonsumsi produk yang ditawarkan pemasar. Menurut McCole (Baskara, 2006) experiential marketing merupakan salah satu bentuk perkembangan pemasaran yang diharapkan dapat menjembatani antara dunia akademis dan praktek. Inti dari experiential marketing adalah membangun hubungan yang langgeng dengan pelanggan. Hal ini juga diperkuat pendapat Schmitt (Kartajaya, 2007) dimana experiential marketing dapat dihadirkan melalui lima unsur yaiitu Sence, Feel, think, act, dan Relate. maka tujuan yang akan dicapai dalam penenlitian ini adalah untuk mengetahui dan menganalisis 
pengaruh experiential marketing, kepuasan konsumen, experiential marketing, kepuasan konsumen, terhadap loyalitas konsumen.

\section{Experiental marketing terhadap kepuasan konsumen}

Penelitian terdahulu tentang experiental marketing terhadap kepuasan konsumen diantaranya Wu \& Tseng (2015) yang meneliti adanya pengaruh experiental marketing terhadap kepuasan pelanggan dan loyalitas pelanggan. Dengan adanya pengalaman sebelumnya maka konsumen akan merasakan kepuasan kepuasan pasca merasakan barang merasakan produk atau jasa tersebut. Penggunaan dimensi yang sama yaitu : sence, feel, act, relate yang dikemukakan Schmit menjadi dasar dalam penentuan indicator-indikator dalam penelitian. Wijaya (2014) menyatakan experiential marketing mempengaruhi benak konsumen agar konsumen ingin melakukan pembelian ulang. Experiential marketing juga mungkin akan menimbulkan kepuasan konsumen yang kemudian akan mempengaruhi pembelian ulang produk tersebut. Hasil penelitian Wahyuningtyas et al. (2017) serta Muhammad \& Artanti (2016) menyatakan bahwa ada hubungan antara experimental marketing dengan kepuasan pelanggan dan loyalitas pelanggan. Demikian pula Devindiani \& Wibowo (2016) menyatakan bahwa experimental marketing dengan memiliki pengaruh positif dan signifikan pada kepuasan serta loyalitas pelanggan.

\section{Kepuasan konsumen terhadap loyalitas konsumen}

Dalam penelitian yang dilakukan oleh Safitri et al. (2015) yang meneliti tentang kepuasan pelanggan terhadap loyalitas di rumah sakit, kesimpulan dalam penelitian ini terdapat pengaruh kepuasan terhadap loyalitas pasien. Penelitian Shandra \& Murwatiningsih (2016) menyatakan bahwa kepuasan konsumen akan mempengaruhi loyalitas, kepuasan konsumen memediasi kualitas layanan terhadap loyalitas. Demikian pula hasil penelitian Kasiri et al. (2017) dan Jiang \& Zhang (2016) menyatakan bahwa kepuasan pelanggan memiliki efek yang signifikan pada loyalitas pelanggan. Penelitian Famiyeh et al. (2018) menyatakan adanya hubungan kepuasan nasabah dan loyalitas nasabah perbankan, dijelaskan lebih lanjut jika nasabah puas dengan produk dan layanan bank, maka kemungkinan besar nasabah akan tetap loyal terhadap bank tersebut.

Untuk menciptakan loyalitas konsumen perusahaan harus mampu memberikan kesan atau pengalaman terhadap konsumen, semakin positif kesan atau pengalaman yang diterima oleh konsumen semakin besar terwujudnya loyalitas konsumen dan tidak menutup kemungkinan akan terwujudnya rasa puas yang nantinya sebagai mediasi untuk terbentuknya loyalitas konsumen. Berdasarkan landasan teori dan konsep yang dijabarkan maka penelitian ini akan menganalisis pengaruh dari experiental marketing terhadap loyalitas konsumen dengan consumer satisfaction (kepuasan konsumen) sebagai variabel mediasi. 
Penelitian (Nurcahyo, 2016) menyatakan bahwa kepuasan pelanggan tidak berperan pada hubungan antara experimental marketing pada loyalitas pelanggan. Sedangkan penelitian Wahyuningtyas et al. (2017) bahwa experimental marketing terbukti mempengaruhi kepuasan pelanggan, temuan lain dinyatakan bahwa kepuasan pelanggan akan meningkatkan loyalitas pelanggan.

Dalam penelitian ini terdapat terdapat tiga variabel yang akan diteliti, yaitu experiental marketing sebagai variabel independen, loyalitas konsumen sebagai variabel dependen dan kepuasan konsumen sebagai variabel mediasi.

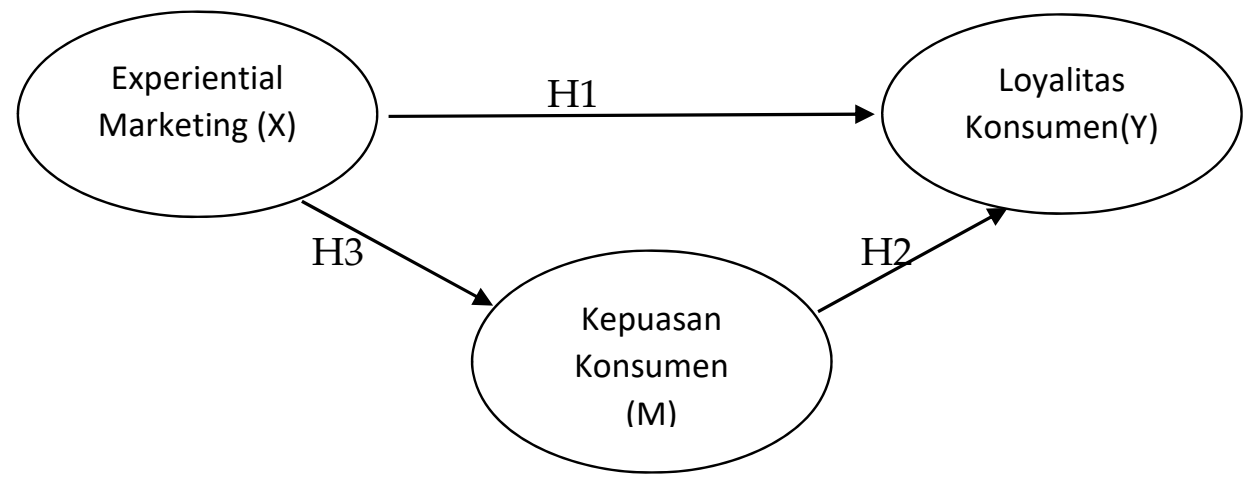

\section{Gambar 1. Kerangka Konseptual}

Hipotesis penelitian dirumuskan sebagai berikut:

H1: Experiental marketing berpengaruh positif terhadap loyalitas konsumen

$\mathrm{H} 2$ : Kepuasan konsumen berpengaruh positif terhadap loyalitas konsumen

H3: Experiental marketing berpengaruh positif terhadap kepuasan konsumen

\section{Metode}

Penelitian ini merupakan penelitian eksplanasi (explanatory research), menurut penelitian yang menjelaskan hubungan antara variabel-variabel penelitian melalui pengujian hipotesis. Metode yang digunakan dalam penelitian ini adalah metode kuantitatif. Variabel dalam penelitian ini meliputi antara lain : Penelitian ini menggunakan 3 variabel yang terdiri dari Variabel Independen yaitu Experiental Marketing (X), variabel dependen loyalitas konsumen (Y2) dan Variabel Mediasi kepuasan konsumen (Y1). Objek penelitian yang akan diteliti adalah semua konsumen yang pernah datang pada Jos Café Jombang dan yang sesuai dengan criteria penelitian. Teknik yang digunakan dalam pengambilan sampel adalah dengan cara accidental sampling, yaitu teknik penentuan sampel berdasarkan kebetulan, yaitu siapa saja yang secara kebetulan bertemu dengan peneliti dapat digunakan sebagai sampel, bila dipandang orang yang kebetulan ditemui cocok sebagai sumber data, dengan menyebarkan angket, pengukuran nilai dari angket ini 
menggunakan skala Likert. Teknik analisis data yang digunakan adalah Path Analysis.

\section{Hasil}

\section{Pengaruh Experiental Marketing terhadap loyalitas konsumen}

Pengujian awal dilakukan analisis regresi antara experiental marketing dengan loyalitas konsumen, tanpa melibatkan variabel kepuasan konsumen. Hasil analisis disajikan pada tabel 1.

Tabel 1. Hasil analisis regresi model awal (pengaruh langsung)

\begin{tabular}{lccc}
\hline \multicolumn{1}{c}{ Variabel Bebas } & Beta & T & Sig. \\
\hline Experiental marketing & 0.429 & 4.702 & .000 \\
\hline Variabel terikat & Loyalitas pelanggan & \\
\hline
\end{tabular}

Sumber: data diolah

Koefisien beta (Standardized coefficient) experiental marketing sebesar 0.429 menunjukkan bahwa experiental marketing memiliki pengaruh positif terhadap loyalitas pelanggan, selanjutnya nilai signifikan 0.000 lebih kecil dari 0,05 berarti experiential marketing berpengaruh signifikan terhadap loyalitas konsumen.

\section{Pengujian experiental marketing, dan kepuasan konsumen terhadap loyalitas konsumen}

Tabel 2. Hasil analisis regresi (model 1)

\begin{tabular}{lccc}
\hline \multicolumn{1}{c}{ Variabel Bebas } & Beta & $\mathrm{T}$ & Sig. \\
\hline Experiental marketing & 0.074 & 1.739 & 0.085 \\
Kepuasan konsumen & 0.892 & 21.107 & 0.000 \\
\hline Variabel terikat & Loyalitas pelanggan & & \\
\hline
\end{tabular}

Sumber: data diolah

Koefisien beta (Standardized coefficient) experiental marketing sebesar 0.074 menunjukkan bahwa experiental marketing memiliki pengaruh positif terhadap loyalitas pelanggan, selanjutnya nilai signifikan 0.085 lebih besar dari 0,05 berarti experiential marketing tidak berpengaruh signifikan terhadap loyalitas konsumen, dengan demikian Hipotesis 1 ditolak. Hasil analisis ini menunjukkan bahwa setelah memasukkan variabel kepuasan konsumen pada hubungan kausal antara experiental marketing dengan loyalitas konsumen, ternyatan experiental marketing tidak berpengaruh signifikan.

Koefisien beta (Standardized coefficient) kepuasan konsumen sebesar 0.892 menunjukkan bahwa kepuasan konsumen memiliki pengaruh positif terhadap loyalitas pelanggan, selanjutnya nilai signifikan 0.000 lebih kecil dari 0,05 berarti 
kepuasan konsumen berpengaruh signifikan terhadap loyalitas konsumen, dengan demikian Hipotesis 2 diterima.

\section{Pengaruh Experiental Marketing terhadap kepuasan konsumen}

Tabel 3. Hasil analisis regresi (model 2)

\begin{tabular}{lccc}
\hline \multicolumn{1}{c}{ Variabel Bebas } & Beta & T & Sig. \\
\hline Experiental marketing & 0.397 & 4.286 & 0.000 \\
\hline Variabel terikat & Kepuasan konsumen & & \\
\hline
\end{tabular}

Sumber: data diolah

Koefisien beta (Standardized coefficient) experiental marketing sebesar 0.397 menunjukkan bahwa experiental marketing memiliki pengaruh positif terhadap kepuasan konsumen, selanjutnya nilai signifikan 0.000 lebih kecil dari 0,05 berarti experiental marketing berpengaruh signifikan terhadap kepuasan konsumen, dengan demikian Hipotesis 3 diterima.

Berdasarkan hasil analisis pada coefficient maka dapat dibuat model hasil analisis sebagai berikut :
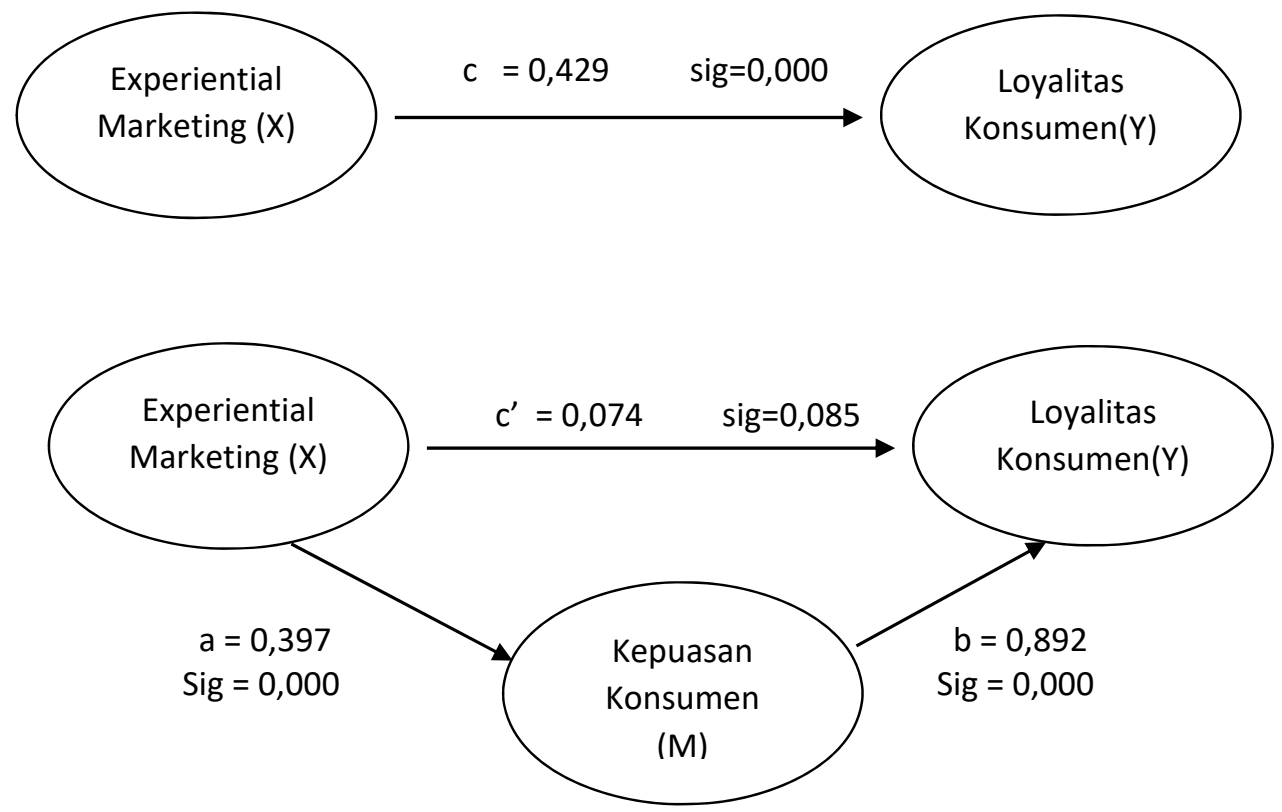

Gambar 2. Hasil Analisis Jalur

Berdasarkan hasil analisis diatas diketahui bahwa variabel bebas (Experiential Marketing) berpengaruh terhadap variabel mediasi (kepuasan konsumen). Variabel mediasi (kepuasan konsumen ) berpengaruh terhadap loyalitas konsumen. Tetapi pengaruh variabel bebas (Experiential Marketing) menjadi tidak berpengaruh 
terhadap variabel tergantung (loyalitas konsumen), setelah memasukkan variabel mediasi (kepuasan konsumen). Sehingga dapat disimpulkan kepuasan konsumen memediasi secara mutlak hubungan antara experiential marketing dengan loyalitas konsumen.

\section{Pembahasan}

\section{Pengaruh Experiental Marketing terhadap loyalitas konsumen}

Berdasarkan hasil analisis inferensial menunjukkan bahwa Experiental Marketing tidak menumbuhkan tingkat loyalitas konsumen Jos café Jombang. dengan kata lain tinggi rendahnya penerapan Experiental Marketing secara langsung tidak mengakibatkan tingkat loyalitas konsumen di Jos Café Jombang meningkat, dengan hidangan makanan dan minuman yang kurang membangkitkan rasa ingin tahu dari konsumen, atau tidak membuat konsumen penasaran akan menu yang disajikan. Membuat konsumen enggan untuk berkunjung kembali ke Jos Café Jombang.

Selain itu penerapan konsep Experiental Marketing di Jos Café Jombang kurang didukung dengan perlengkapan Café. Misalnya dari segi panca indera penglihatan, fasilitas Televisi sering terlihat tidak menyala. Dari panca indera pendengaran juga seperti itu pengeras suara yang ada di Jos Café juga tidak menyala Sehingga membuat konsumen kekurangan hiburan saat berada di Jos café Jombang. Dari warna dinding juga lebih monoton tanpa ada tulisan atau gambar-gambar yang unik yang membuat konsumen merasa nyaman dan senang, sehingga konsumen mudah merasa bosan dan merasa biasa dengan tempat tempat lainya. Desain tata ruang dari Jos café Jombang juga terlihat tidak ada perbedaan yang unik dari kedai -kedai café yang lain. Temuan penelitian mendukung penelitian sebelumnya dari $\mathrm{Wu} \&$ Tseng (2015), Wijaya (2014), dan Devindiani \& Wibowo (2016) yang menyatakan experiental marketing akan mempengaruhi kepuasan pelanggan.

Kualitas layanan dari para pegawai jos café sudah ramah akan tetapi kurang Friendly. Padahal saat ini konsumen akan lebih merasa nyaman dan senang apabila kita dilayani seramah mungkin dan serasa seperti sahabat atau keluarga sendiri. Sehingga konsumen tidak merasa canggung untuk bertanya atau ngobrol dengan para pegawai Jos café. sehingga konsumen akan timbul rasa ingin tahu dan selalu ingin kembali ke Jos café dengan Tujuan Makan, nongkrong, Bertemu dengan relasi kerja. Padahal menurut Zeithaml et al. (2000) mengatakan bahwa tugas dari keberhasilan sebuah perusahaan yang menjalin hubungan yang baik dengan konsumenya adalah untuk membentuk loyalitas yang kuat.

\section{Pengaruh kepuasan konsumen terhadap loyalitas konsumen}

Berdasarkan hasil analisis inferensial menunjukkan bahwa kepuasan konsumen mengakibatkan tingginya tingkat loyalitas konsumen di Jos café Jombang, dengan kata lain apabila kepuasan konsumen tinggi akan diikuti loyalitas 
konsumen di Jos café. Temuan penelitian ini mendukung penelitian dari Safitri et al. (2015), Shandra \& Murwatiningsih (2016), Kasiri et al. (2017) dan Jiang \& Zhang (2016) menyatakan bahwa kepuasan pelanggan memiliki efek yang signifikan pada loyalitas pelanggan. Dengan konsep overall satisfaction konsumen akan merasa puas dengan berbagai hal yang ada di Jos Café Jombang, misalnya konsumen merasa puas akan layanan yang diberikan oleh pihak Jos café maka konsumen akan berkunjung kembali ke Jos café dengan kepentingan masing-masing.

Dari segi keseluruhan tata ruangan di Jos café memuaskan konsumen dengan tata ruang yang rapi dan bersih akan membangkitkan keinginan untuk kembali ke Jos café. dan bersedia untuk melakukan pembelian ulang di Jos café Jombang. Apabila sudah merasa puas menjadi konsumen Jos café Jombang. maka konsumen akan terus melakukan pembelian ulang. Tidak hanya itu konsumen juga bersedia merekomendasikan kepada orang lain agar melakukan pembelian ke Jos café Jombang. dengan kepentingan masing-masing. Misalnya makan dengan teman, makan dengan relasi kerja, ataupun sebatas nongkrong.

\section{Pengaruh Experiental Marketing terhadap kepuasan konsumen}

Berdasarkan hasil analisis inferensial menunjukkan bahwa Experiental Marketing dapat membuat tinggi rendahnya tingkat kepuasan konsumen di Jos café Jombang. dengan kata lain apabila Experiental Marketing tinggi akan diikuti kepuasan konsumen di Jos café. Temuan penelitian ini mendukung penelitian sebelumnya dari Wahyuningtyas et al. (2017) serta Muhammad \& Artanti (2016) menyatakan bahwa ada hubungan antara experimental marketing dengan kepuasan pelanggan. Demikian pula Devindiani \& Wibowo (2016) menyatakan bahwa experimental marketing dengan memiliki pengaruh positif dan signifikan pada kepuasan serta.

Penerapan konsep Experiental Marketing yang tepat di Jos café Jombang membuat konsumen merasa lebih puas. Sesuai dengan teori yang dikemukakan oleh Garbarino \& Johnson (2001), kepuasan secara keseluruhan berdasarkan pada pembelian dan pengalaman mengkonsumsi barang dan jasa. Pengalaman yang baik dan mengesankan akan menciptakan timbulnya perasaan positif atau perasaan puas dan emosi terhadap suatu perusahaan atau meek tertentu. Jadi kepuasan konsumen dapaat terbentuk apabila konsumen merasakan kenyamanan dalam hubunganya perusahaan dan apa yang dia dapatkan sama dengan harapan yang diinginkan. Andreani (2007), menyatakan dengan adanya Experiental Marketing konsumen akan mampu membedakan produk dan jasa yang satu dengan yang lainya. Karena mereka dapat merasakan dan memperoleh pengalaman secara langsung, baik sebelum, saat menggunakan maupun sesudah. Sehingga akan timbul rasa puas atau pun tidak puas dari pembelian yang sudah dilakukan. 


\section{Pengaruh Experiential Marketing terhadap loyalitas konsumen dengan kepuasan konsumen}

Berdasarkan hasil uji Sobel menunjukan bahwa nilai experiential Marketing terhadap loyalitas konsumen melalui kepuasan konsumen sebagai variabel mediasi lebih besar dibanding hubungan langsung experiential marketing terhadap loyalitas konsumen, artinya untuk membuat konsumen loyal maka perusahaaan harus menciptakan sesuatu yang membuat konsumen merasa puas. Temuan ini sejalan dengan penelitian Wahyuningtyas et al. (2017) bahwa experimental marketing terbukti mempengaruhi kepuasan pelanggan, temuan lain dinyatakan bahwa kepuasan pelanggan akan meningkatkan loyalitas pelanggan. Namun bertentangan dengan temuan penelitian Nurcahyo (2016) menyatakan bahwa kepuasan pelanggan tidak berperan pada hubungan antara experimental marketing pada loyalitas pelanggan.

Untuk menjadikan konsumen menjadi loyal tidak lah mudah hal ini disebabkan terdapat banyak tantangan yang harus dihadapi dan dipertimbangkan agar konsumen menjadi loyal. Secara konsep dapat dikatakan bahwa untuk menjadi loyal maka konsumen harus merasa puas terlebih dahulu. Perusahaan harus benarbenar memenuhi keinginan dan kebutuhan konsumen agar konsumen merasa benar benar puas dan tetap bertahan. Menurut Mowen \& Michael (2005) kepuasan konsumen merupakan keseluruhan sikap konsumen setelah memperoleh dan menggunakan barang dan jasa. Oleh karena itu perusahaan harus benar-benar mampu memenuhi keinginan dan kebutuhan konsumen dan lebih jauh lagi dapat menciptakan loyalitas konsumen. Konsep Experiental Marketing yang sesuai dapat membuat konsumen merasa puas akan produk yang diberikan. Setelah konsumen merasa puas dengan produk dan layanan yang diberikan maka konsumen akan bersedia menjadi konsumen yang loyal. Untuk meningkatkan loyalitas konsumen maka tingkat kepuasan konsumen harus ditingkatkan dengan penerapan Experiential Marketing semaksimal mungkin.

\section{Simpulan}

Berdasarkan hasil penelitian dengan pengumpulan data dari responden dari konsumen Jos café Jombang sebagai responden dan analisa data untuk masing masing model maka kesimpulan yang diperoleh bahwa) Experiental Marketing tidak memiliki peran untuk membuat meningkatnya loyalitas konsumen di Jos café Jombang karena penerapan konsep Experiential Marketing yang kurang maksimal membuat konsep ini tidak berperan untuk meningkatkan loyalitas konsumenya. Temuan lain bahwa konsumen bersedia menjadi konsumen yang loyal apabila konsumen tersebut merasa puas saat berada di Jos café Jombang. Puas dari segi pelayanan, puas dari segi menu makanan dan minuman yang sesuai harapan konsumen dan puas menjadi konsumen jos café jombang. Penerapan konsep Experiental Marketing akan membuat konsumen merasa puas saat berada di Jos café 
Jombang. Experiental Marketing bisa membuat konsumen menjadi loyal dengan membuat konsumen merasa puas saat berada di Jos café Jombang, begitupun sebaliknya apabila konsumen tidak merasa puas konsep Experiential Marketing tidak bisa berperan untuk meningkatkan loyalitas konsumen. Untuk penelitian selanjutnya diharapkan menambahkan variabel lain faktor lain yang bisa meningkatkan loyalitas konsumen seperti harga kompetitif, promosi, dan kualitas layanan.

\section{Daftar Pustaka}

Baskara, A. H. (2006). Teori umum Experiental Marketing. Jakarta: Erlangga.

Devindiani, E., \& Wibowo, L. A. (2016). Pengaruh Experiential Marketing terhadap Customer Satisfaction Serta Dampaknya pada Customer Loyalty (Survei pada Pengguna Smartphone di Komunitas Online Apple dan Samsung Regional Bandung). Journal of Business Management Education (JBME), 1(1), 149-159.

Famiyeh, S., Asante-Darko, D., \& Kwarteng, A. (2018). Service quality, customer satisfaction, and loyalty in the banking sector. International Journal of Quality $\mathcal{E}$ Reliability Management, 35(8), 1546-1567.

Jeon, H. (2013). The effect of experiential marketing on customer satisfaction and revisit intention of beauty salon franchise stores. Journal of Fashion Business, 17(3), 109-121.

Jiang, H., \& Zhang, Y. (2016). An investigation of service quality, customer satisfaction and loyalty in China's airline market. Journal of Air Transport Management, 57, 80-88.

Kartajaya, H. (2002). Hermawan Kartajaya on Marketing. Gramedia Pustaka Utama.

Kartajaya, H. (2007). Hermawan Kartajaya on Marketing Mix. Mizan Pustaka.

Kasiri, L. A., Cheng, K. T. G., Sambasivan, M., \& Sidin, S. M. (2017). Integration of standardization and customization: Impact on service quality, customer satisfaction, and loyalty. Journal of Retailing and Consumer Services, 35, 91-97.

Mowen, J. C., \& Michael, M. (2005). Consumer Behaviour. Prentice-Hall.

Muhammad, M., \& Artanti, Y. (2016). The impact of experiential marketing on word of mouth with customer satisfaction as a intervening variable. JDM (Jurnal Dinamika Manajemen), 7(2), 182-190.

Nurcahyo, B. (2016). The role of customer satisfaction in a relation of experiential marketing and customer loyalty. Advances in Social Sciences Research Journal, 3(1). 
Pine, B. J., \& Gilmore, J. H. (2011). The experience economy. Harvard Business Press.

Safitri, D. N., Hidayat, W., \& Dewi, R. S. (2015). Pengaruh Kualitas Pelayanan, Lokasi, Dan Tarif Terhadap Kepuasan Pasien Rawat Inap Rumah Sakit Lestari Raharja Kota Magelang (Studi Kasus Pada Pasien Rawat Inap Non Asuransi). Jurnal Ilmu Administrasi Bisnis, 4(2), 325-331.

Schmitt, B. (1999). Experiential marketing. Journal of Marketing Management, 15(1-3), 53-67.

Shandra, M. P. K., \& Murwatiningsih, M. (2016). Kepuasan Konsumen sebagai Mediasi Pengaruh Kualitas Pelayanan, Brand Image dan Harga terhadap Loyalitas Konsumen pada Taksi New Atlas Semarang. Management Analysis Journal, 5(1).

Wahyuningtyas, F. M., Achmad, F., \& Zainul, A. (2017). The effect of experiential marketing on satisfaction and its impact on customer loyalty. Russian Journal of Agricultural and Socio-Economic Sciences, 61(1).

Wijaya, A. (2014). Analisis Pengaruh Experiential Marketing Terhadap Repeat Purchase Dengan Customer Satisfaction Sebagai Experiential Marketing. Jurnal Strategi Pemasaran, 2(1), 1-9.

Wu, M.-Y., \& Tseng, L.-H. (2015). Customer satisfaction and loyalty in an online shop: An experiential marketing perspective. International Journal of Business and Management, 10(1), 104.

Zarem, J. E. (2000). Experience marketing. Folio: The Magazine for Magazine Management, 1(3), 28-32.

Zeithaml, V. A., Parasuraman, A., \& Berry, L. L. (2000). Measuring the quality of relationship in customer service: An empirical study. Journal of Marketing. 